Int. J. Electrochem. Sci., 14 (2019) $2984-2998$

\title{
First-Step Anodization of Commercial Aluminium in Oxalic Acid: Role of Anodization Voltage in Tailoring the Structural Features of Porous Alumina Film and Aluminium Substrate
}

\author{
S. M. Junaid Zaidi ${ }^{1}$ and M. Z. Butt ${ }^{2, *}$ \\ ${ }^{1}$ Department of Physics, GC University, Lahore-54000, Pakistan \\ ${ }^{2}$ Centre for Advanced Studies in Physics, GC University, Lahore 54000, Pakistan \\ *E-mail: mzakriabutt@gmail.com
}

doi: $10.20964 / 2019.03 .11$

Received: 23 June 2018 / Accepted: 19 July 2018 / Published: 7 February 2019

\begin{abstract}
Commercially pure $\mathrm{Al}$ specimens were anodized in $0.3 \mathrm{M}$ oxalic acid at $0{ }^{\circ} \mathrm{C}$ for 15 min using five different anodization voltages in the range $10-50 \mathrm{~V}$. Current versus time transient plots for each anodization voltage were recorded via computer interfaced multimeter. Current density, amount of charge transferred, and thickness of anodized film were found to increase linearly with the increase in anodization voltage. Scanning electron microscope studies of the first - step anodized nanoporous alumina films show that the pore diameter, interpore distance and porosity increase linearly with the increase in anodization voltage. On the contrary, the pore circularity and pore density decrease linearly with the increase in anodization voltage. XRD studies of the un-anodized and anodized Al specimens show that the peak intensity of (111), (200), and (311) planes decreases with the increase in anodization voltage whereas reverse is true for the preferentially oriented (220) plane. The nature of lattice strain is compressive (-) for the anodization voltages 20 and $50 \mathrm{~V}$, as is also the case with un-anodized $\mathrm{Al}$ specimen, and tensile (+) for 10, 30, and $40 \mathrm{~V}$.
\end{abstract}

Keywords: Anodic alumina; Anodization voltage; Film thickness; X-ray diffraction; Scanning electron microscopy; Structural features

\section{$\underline{\text { FULL TEXT }}$}

(C) 2019 The Authors. Published by ESG (www.electrochemsci.org). This article is an open access article distributed under the terms and conditions of the Creative Commons Attribution license (http://creativecommons.org/licenses/by/4.0/). 